\title{
BMJ Open Factors associated with the clinical outcomes of paediatric out-of-hospital cardiac arrest in Japan
}

\author{
Takashi Nagata, ${ }^{1}$ Takeru Abe, ${ }^{2}$ Eiichiro Noda, ${ }^{3}$ Manabu Hasegawa, ${ }^{4}$ \\ Makoto Hashizume, ${ }^{1}$ Akihito Hagihara ${ }^{5}$
}

To cite: Nagata T, Abe T, Noda $\mathrm{E}$, et al. Factors associated with the clinical outcomes of paediatric outof-hospital cardiac arrest in Japan. BMJ Open 2014;4: e003481. doi:10.1136/ bmjopen-2013-003481

- Prepublication history for this paper is available online. To view these files please visit the journal online (http://dx.doi.org/10.1136/ bmjopen-2013-003481).

Received 1 July 2013 Revised 3 January 2014 Accepted 14 January 2014

CrossMark

For numbered affiliations see end of article.

Correspondence to

Professor Akihito Hagihara; hagihara@hsmp.med.kyushuu.ac.jp

\section{ABSTRACT}

Objectives: To better understand and predict clinical outcomes of paediatric out-of-hospital cardiac arrest (OHCA).

Design: A population-based, observational study.

Setting: The National Japan Utstein Registry. Participants: 2900 children aged 5-17 years who experienced OHCA and received resuscitation by emergency responders. Signal detection analysis using 17 variables was applied to identify factors associated with OHCA outcomes; the primary endpoint was cerebral performance category (CPC) 1 or 2. A validation study was conducted to verify the model.

Results: OHCA was identified as cardiac origin in 706 participants and non-cardiac origin in 2194 participants. Rates of CPC 1 or 2 for cardiac and noncardiac causes were $20 \%$ and $6.4 \%$, respectively. Cardiac origin arrest was categorised following signal detection into six subgroups defined by public automated external defibrillator use, defibrillation by emergency medical service, age, initial ECG rhythm and eye-witness to arrest; the ranges of CPC 1 or 2 in the six subgroups were between $87.5 \%$ and $0.7 \%$. Non-cardiac origin arrest was categorised into four subgroups. Bystander rescue breathing was the most significant factor contributing to outcome; additionally, two other factors-eye-witness to arrest and agewere also significant. CPC 1 or 2 rates ranged between $38.5 \%$ and $4 \%$ across the four subgroups. Rates of CPC 1 or 2 in the validation study did not differ among any subgroup.

Conclusions: For children who have OHCA from noncardiac origin, bystander rescue breathing is mandatory to achieve CPC 1 or 2.

\section{INTRODUCTION}

Paediatric out-of-hospital cardiac arrest (OHCA) is an uncommon event, but is generally associated with poor survival and longterm neurological outcomes. ${ }^{1-7}$ Some factors that may contribute to the 1-month survival rate following OHCA in children have been identified, including witnessed cardiac arrest, initial ECG rhythm and bystander

\section{Strengths and limitations of this study}

- This study revealed that public automated external defibrillator (AED) use was a significant predictor of cerebral performance category $\mathrm{n}(\mathrm{CPC})$ 1 or 2 outcomes for cardiac origin out-of-hospital cardiac arrest (OHCA), and bystander rescue breathing for non-cardiac origin OHCA among children aged $5-17$ years.

- By using signal detection analysis, the issues of the multicolinearity and interactions among variables can be resolved.

- Variables regarding the treatment in the hospital were not included in the analysis.

cardiopulmonary resuscitation (CPR); however, these factors were not investigated for an effect on long-term prognosis after resuscitation. ${ }^{58}{ }^{9}$ Factors affecting long-term prognosis following OHCA in adults have been studied, and Dumas et $a l^{10}{ }^{11}$ reported that chest compression alone CPR or shockable initial ECG rhythms were significantly associated with long-term prognosis in adults. Nonetheless, a gap remains in our understanding of the OHCA-related features that can predict clinical outcomes in children experiencing these events.

Importantly, the statistical analyses used in most of the previous studies of factors affecting OHCA outcomes were based on the $\chi^{2}$ test with stratification, multivariate regression analysis or linear regression analysis. ${ }^{12} 13$ These statistical methods are effective when a model includes the interaction of two variables. However, if a model includes the interaction of three or more variables, there is typically a problem of multicolinearity, and the interpretation of higher-order interaction is complex. To address these problems, the signal detection analysis (SDA) method has been advocated by Kraemer. ${ }^{14-16}$ SDA recursively reveals the strongest interaction of factors among groups, based on the largest $\chi^{2}$ statistic and 
significant probability $(\mathrm{p}<0.05)$, and in the absence of that factor, the remaining factors are again analysed recursively. Thus, SDA is a prediction tool like a recursive partitioning analysis or decision tree analysis, wherein a combination of factors can explain the probability of an outcome.

The purposes of this study were (1) to identify factors associated with long-term neurological prognosis following OHCA in children, (2) to identify distinct subgroups with the high probability of good long-term neurological prognosis and (3) to consider the prediction of OHCA by using subgroups and identified factors and develop effective prevention programmes for OHCA in children. ${ }^{17}$

\section{METHODS}

\section{Study setting}

The National Japan Utstein Registry at the Fire and Disaster Management Agency (FDMA), Japan, is a prospective, nationwide, population-based registry for OHCA. ${ }^{18}$ This observational study included all paediatric (aged 5-17 years) OHCA cases registered between 1 January 2007 and 31 December 2010, treated by emergency medical service (EMS) personnel and transported to hospitals during the study period. A detailed description of the Japan Utstein Registry has been reported in other studies. ${ }^{19-21}$ In this study, OHCA by external causes was excluded from the study population. The FDMA provided the anonymous data, and written informed consent was waived.

\section{Study variables, outcomes and predictors}

Data were collected prospectively by FDMA with a form that queries gender, age, causes of cardiac arrest, bystander's witness status, first documented ECG, presence and type of CPR by bystander, and intubation and administration of epinephrine by EMS personnel. The outcome variable assessed in this study was cerebral performance categories (CPCs) of the Glasgow-Pittsburgh Outcome Categorization of Brain Injury, which scores cerebral function from 1 (normal) to 5 (brain death). ${ }^{22}$ CPC, which was assessed here 1 month after OHCA, is more suitable than return of spontaneous circulation before hospital arrival or 1-month survival after the event because CPC reflects the quality of life after the event. $^{23}$ Explanatory variables were categorised into three information groups: demographic and transport, basic life support provided by a bystander and advanced life support provided by EMS personnel. Demographic and transport information included gender, age, the presence of life-saving technician in the ambulance, the presence of a medical doctor in the ambulance, time from emergency call to ambulance arrival on the scene, time from emergency call to hospital arrival and initial ECG waveform. Information about basic life support provided by a bystander included chest compression, rescue breathing and automated external defibrillator (AED) use. Information about advanced life support provided by EMS personnel included defibrillation by emergency medical personnel, advanced airway device use, obtaining intravenous access and epinephrine injection. Cases with missing data for age and other variables were excluded from further analyses.

\section{Statistical analysis}

Descriptive analyses using the entire sample were conducted first, and t test or tests of independence were used to compare cardiac origin OHCA and non-cardiac origin OHCA. Next, the study data were randomly divided into two samples as a split-half method ${ }^{2425}$ : one for a prediction analysis (sample $1, \mathrm{n}=1450$ ) and the other for a validation analysis (sample 2, $\mathrm{n}=1450$ ). Randomisation was performed using SPSS software (V.19; SPSS, Chicago, Illinois, USA). Cross-validation was performed on all study variables between samples 1 and 2 , using a t test for a continuous variable or a $\chi^{2}$ test for categorical variables. Test results of non-significance would guarantee validity of randomisation, and, subsequently, homogeneity between samples 1 and $2 .{ }^{24} 25$

We used SDA (ROC 5.0 software) to develop a prediction model for the outcome of OHCA in children. Based on previous studies, analysis included 17 essential variables, including basic information (age, gender, medical staff ride, etc), cardiac arrest witness and bystander CPR, and diagnosis and treatment at the hospital. These 17 variables produce in excess of millions of possible combinations. Logistic regression or linear regression analyses cannot adequately deal with every possible combination.

Here, we sought to develop a predictive model (prediction sample) of clinical outcome for paediatric OHCA by using SDA on nationwide Utstein-style data available in Japan, and to subsequently confirm the validity of this model (validation sample).

SDA was performed on sample 1 to identify factors related to the proportion of cases evaluated as CPC 1 or 2 compared with CPC 3, 4 or 5. SDA is known as a recursive partitioning and nonparametric process and assesses combinations of independent variables that are categorised into two subgroups according to selected criteria, for example, dichotomous variables or a certain cut-off point for a continuous variable. The identified subgroups by SDA were mutually exclusive and maximally discriminating subgroups for a dichotomous outcome. SDA is approximately applicable for an explanatory analysis, especially when it is necessary to measure higher-order interactions among independent variables because of clinical evidence. Thus, linearity and normality in residuals from the model's equation or multicolinearity among independent variables, as in a multivariate analysis, are not necessary to be considered. The SDA partitioning process identifies unknown combinations of certain independent variables to maximise the sensitivity and specificity in predicting patient outcome. The optimally efficient variable or cut-off point is determined by the maximum weighted-к coefficient. After selecting the first variable, the programme 
will repeat partitioning for each subgroup using all of the independent variables until the stopping-rules are applied. The stopping-rules for the partitioning processes were triggered when (1) less than 10 patients appeared in a subgroup, (2) no variable was found with significant level, $p<0.05$ and $(3)<0$ values were in the lower limits of the $95 \%$ CI of the maximum weighted-א coefficient.

The Cochrane-Mantel-Haenszel test was performed to compare CPC 1 or 2 proportion between the prediction and validation samples, stratified by the subgroups. ${ }^{21} 2425$ The validation sample (sample 2) was categorised into mutually exclusive subgroups based on the information from the SDA in the prediction sample (sample 1). The split-sample will be validated if no significant difference in CPC 1 or 2 proportion is found between samples 1 and 2 . The mutually exclusive subgroups were created in sample 1 according to the critical variable cut-off points found using SDA in the first sample. Support for split-half method validation would occur if no significant differences in levels of inactivity were noted between samples 1 and 2 for the paired subgroups identified. Applying Cochrane-Mantel-Haenszel test was exploratory in nature and provided a more complete picture of the characteristics of each subgroup. In addition, we calculated $\mathrm{d}^{\prime}$ and area under the curve in receiver operating curve (AUC-ROC) to check the validity of randomisation.

Using all the samples, the subgroups were compared according to the study variables listed in tables 1 and 2 . Analysis of variance procedures for continuous variables and tests of independence for dichotomous or discrete variables were used. Two-tailed $p$ values $<0.05$ were deemed to indicate statistical significance. Analyses were conducted using SPSS.

\section{RESULTS}

Out of 461,571 OHCA cases registered by the National Japan Utstein Registry between 2007 and 2010, 2900 paediatric cases were selected in the present analysis, and the remaining cases were excluded according to selection criteria (figure 1). Younger children were excluded because previous findings suggest that cardiac arrest outcomes may differ for children under age $5{ }^{26}$

Descriptive characteristics of the population are shown in tables 1 and 2. Overall, $9.7 \%$ of cases had an outcome of CPC 1 or 2 (20\% for cardiac origin, $6.4 \%$ for noncardiac origin). Compared with non-cardiac origin OHCA, the neurological outcomes of cardiac origin OHCA were significantly better regarding return of spontaneous circulation before hospital arrival, 1-month survival after the event, CPC 1 or 2 and overall performance category 1 or $2(\mathrm{p}<0.001)$. Cross-validation showed that all variables were not significantly different between samples 1 and 2, except bystander chest compression among patients with non-cardiac OHCA.

SDA identified six distinct subgroups in cardiac origin OHCA, and four distinct subgroups in non-cardiac origin OHCA. While descriptive names are provided for each subgroup, the complex sets of clinical information were used for the interpretation of the subgroups. For example, subgroup 6 in cardiac origin OHCA was named as "non-VF/VT without eye witness".

The percentage of cases with CPC scores of 1 or 2 was $21.7 \%$ among cardiac-origin OHCA in the prediction sample (table 1). SDA revealed six subgroups, numbered as shown in figure 2. The percentage of CPC 1 or 2 across the subgroups ranged from $87.5 \%$ to $0.7 \%$. Subgroup 1, characterised as public AED use and no defibrillation by EMS, had the highest percentage of CPC 1 or 2 outcomes $(87.5 \%)$. Subgroup 3 (30.8\% CPC 1 or 2) was characterised as receiving public AED use and EMS defibrillation. Subgroups 2 and 5 were characterised by the condition that there was no public AED use, and the initial ECG showed VF/VT. These two subgroups included a third variable, age of cases. For cases aged 10-17 years (subgroup 2), CPC 1 or 2 was higher (46.8\%); for cases aged 5-9 years (subgroup 5), CPC 1 or 2 was lower $(6.7 \%)$. Subgroups 4 and 6 were characterised by the condition that there was no public AED use and the initial ECG showed asystole or pulseless electrical activity. These subgroups were distinguished by a third variable, eyewitness of event. If the event was eye-witnessed (subgroup 4), CPC 1 or 2 percentage was $15.7 \%$; if it was not eye-witnessed (subgroup 6), CPC 1 or 7 percentage was $0.7 \%$.

The percentage of cases of non-cardiac OHCA with CPC 1 or 2 scores was $6.1 \%$ in the prediction sample (table 2). SDA revealed four subgroups, as numbered in figure 3, with percentages of CPC 1 or 2 ranging from $38.5 \%$ to $4 \%$. Subgroups 1 and 3 were characterised by receiving bystander rescue breathing and eye-witness. These subgroups were distinguished by age of case. If cases were aged between 5 and 12 years (subgroup 1), CPC 1 or 2 percentage was $38.5 \%$; if cases were aged between 13 and 17 years (subgroup 3), CPC 1 or 2 percentage was $8 \%$. Subgroup 2 included cases in which there were no eye-witness or bystander rescue breathing; CPC 1 or 2 was scored in only $9.3 \%$ of cases. Subgroup 4 was also characterised as no bystander rescue breathing and CPC 1 or 2 was scored in $4 \%$ of cases.

Comparisons of CPC 1 or 2 rates among the subgroups identified by SDA showed no significant differences between the prediction sample (sample 1) and validation sample (sample 2) with either cardiac origin OHCA or non-cardiac origin OHCA (tables 3 and 4). In addition, the validation of randomisation was warranted since the AUC-ROC and $\mathrm{d}^{\prime}$ showed that categories of subgroups make a fair prediction of outcomes among sample 1, sample 2 and total samples.

Tables 5 and 6 summarise the six subgroups for cardiac origin OHCA and the four subgroups for noncardiac origin OHCA in children. In addition to the characteristics revealed by SDA, the use of witness and bystander CPR, prehospital diagnosis and treatment varied significantly among subgroups. 
Table 1 Descriptive statistics and cross-validation among patients with OHCA with cardiac origin (2007-2010)

\begin{tabular}{|c|c|c|c|c|c|c|c|c|c|}
\hline & & \multicolumn{3}{|c|}{ Total $(n=706)$} & \multirow{2}{*}{\multicolumn{2}{|c|}{$\begin{array}{l}\text { Sample } 1 \\
(\mathrm{n}=360)\end{array}$}} & \multirow{2}{*}{\multicolumn{2}{|c|}{$\begin{array}{l}\begin{array}{l}\text { Sample } 2 \\
(n=346)\end{array} \\
\text { Mean (SD)/ } \\
\text { frequency }(\%)\end{array}$}} & \multirow[b]{2}{*}{ p Value } \\
\hline & & \multicolumn{2}{|c|}{$\begin{array}{l}\text { Mean (SD)/ } \\
\text { frequency (\%) }\end{array}$} & \multirow[t]{2}{*}{ (minimum-maximum) } & & & & & \\
\hline \multicolumn{9}{|l|}{ Basic information } & \\
\hline Gender & (Male) & 438 & $(62.0)$ & & 214 & $(59.4)$ & 224 & $(64.7)$ & 0.15 \\
\hline Age & & 12.52 & (3.73) & $(5-17)$ & 12.56 & (3.71) & 12.47 & (3.77) & 0.73 \\
\hline Emergency life-saving technician on ambulance ride & (Yes) & 679 & (96.2) & & 346 & $(96.1)$ & 333 & (96.2) & 0.93 \\
\hline Medical doctor on ambulance ride & (Yes) & 42 & $(5.9)$ & & 26 & $(7.2)$ & 16 & $(4.6)$ & 0.15 \\
\hline Advance medical treatment by medical doctor & (Yes) & 123 & $(17.4)$ & & 68 & $(18.9)$ & 55 & (15.9) & 0.30 \\
\hline \multicolumn{10}{|l|}{ Witness and bystander CPR } \\
\hline Eye witness of cardiac arrest & (Witnessed) & 395 & $(55.9)$ & & 192 & (53.3) & 203 & $(58.7)$ & 0.15 \\
\hline Type of bystander & (Family member) & 151 & $(21.4)$ & & 71 & $(19.7)$ & 80 & (23.1) & 0.27 \\
\hline Bystander chest compression & (Performed) & 436 & $(61.8)$ & & 227 & (63.1) & 209 & $(60.4)$ & 0.47 \\
\hline Bystander rescue breathing & (Performed) & 229 & (32.4) & & 120 & (33.3) & 109 & (31.5) & 0.60 \\
\hline Bystander AED use & (Performed) & 74 & $(10.5)$ & & 37 & (10.3) & 37 & $(10.7)$ & 0.86 \\
\hline \multicolumn{10}{|l|}{ Preshospital diagnosis and treatment } \\
\hline Initial ECG waveform & (VF or pulseless VT) & 193 & $(27.3)$ & & 103 & $(28.6)$ & 90 & $(26.0)$ & 0.44 \\
\hline Defibrillation provided by emergency medical personnel & (Performed) & 233 & (33.0) & & 121 & (33.6) & 112 & (32.4) & 0.73 \\
\hline Advanced airway device use & (Performed) & 183 & $(25.9)$ & & 102 & (28.3) & 81 & $(23.4)$ & 0.14 \\
\hline Obtaining intravenous route & (Performed) & 92 & (13.0) & & 50 & (13.9) & 42 & $(12.1)$ & 0.49 \\
\hline Epinephrine injection & (Performed) & 33 & $(4.7)$ & & 18 & $(5.0)$ & 15 & $(4.3)$ & 0.68 \\
\hline Scene arrival time from emergency call (minimum) & & 6.64 & (2.69) & $(0-21)$ & 6.67 & $(2.70)$ & 6.61 & $(2.69)$ & 0.75 \\
\hline Hospital arrival time from emergency call (minimum) & & 32.16 & $(22.51)$ & $(5-469)$ & 31.63 & $(14.85)$ & 32.72 & $(28.38)$ & 0.52 \\
\hline \multicolumn{10}{|l|}{ Outcome } \\
\hline Return of spontaneous circulation before hospital arrival & (Yes) & 150 & $(21.2)$ & & 83 & $(23.1)$ & 67 & $(19.4)$ & 0.23 \\
\hline 1-month survival after the event & (Yes) & 185 & (26.2) & & 95 & $(26.4)$ & 90 & (26.0) & 0.91 \\
\hline Cerebral perfusion category & (1 or 2$)$ & 141 & $(20.0)$ & & 78 & $(21.7)$ & 63 & $(18.2)$ & 0.25 \\
\hline Overall performance category & (1 or 2$)$ & 138 & (19.5) & & 78 & $(21.7)$ & 60 & (17.3) & 0.15 \\
\hline
\end{tabular}


Table 2 Descriptive statistics and cross-validation among patients with OHCA with non-cardiac origin (2007-2010)

\begin{tabular}{|c|c|c|c|c|c|c|c|c|c|}
\hline & & \multicolumn{3}{|c|}{ Total $(n=2194)$} & \multicolumn{2}{|c|}{$\begin{array}{l}\text { Sample } 1 \\
(n=1090)\end{array}$} & \multicolumn{2}{|c|}{$\begin{array}{l}\text { Sample } 2 \\
(n=1104)\end{array}$} & \multirow[b]{2}{*}{ p Value } \\
\hline & & \multicolumn{2}{|c|}{$\begin{array}{l}\text { Mean (SD)/ } \\
\text { frequency (\%) }\end{array}$} & $\begin{array}{l}\text { (minimum- } \\
\text { maximum) }\end{array}$ & \multicolumn{2}{|c|}{$\begin{array}{l}\text { Mean (SD)/ } \\
\text { frequency (\%) }\end{array}$} & \multicolumn{2}{|c|}{$\begin{array}{l}\text { Mean (SD)/ } \\
\text { frequency (\%) }\end{array}$} & \\
\hline \multicolumn{10}{|l|}{ Basic information } \\
\hline Gender & (Male) & 1409 & $(64.2)$ & & 721 & $(66.2)$ & 688 & $(62.3)$ & 0.06 \\
\hline Age & & 12.39 & $(4.04)$ & $(5-17)$ & 12.31 & $(4.04)$ & 12.47 & $(4.05)$ & 0.36 \\
\hline Emergency life-saving technician on ambulance ride & (Yes) & 2076 & (94.6) & & 1026 & (94.1) & 1050 & (95.1) & 0.31 \\
\hline Medical doctor on ambulance ride & (Yes) & 120 & $(5.5)$ & & 60 & (5.5) & 60 & $(5.4)$ & 0.94 \\
\hline Advance medical treatment by medical doctor & (Yes) & 411 & $(18.7)$ & & 210 & (19.3) & 201 & $(18.2)$ & 0.53 \\
\hline \multicolumn{10}{|l|}{ Witness and bystander CPR } \\
\hline Eye witness of cardiac arrest & (Witnessed) & 903 & $(41.2)$ & & 454 & $(41.7)$ & 449 & $(40.7)$ & 0.64 \\
\hline Type of bystander & (Family member) & 260 & (11.9) & & 136 & (12.5) & 124 & (11.2) & 0.37 \\
\hline Bystander chest compression & (Performed) & 962 & (43.9) & & 451 & (41.4) & 511 & (46.3) & 0.02 \\
\hline Bystander rescue breathing & (Performed) & 457 & $(20.8)$ & & 214 & $(19.6)$ & 243 & (22.0) & 0.17 \\
\hline Bystander AED use & (Performed) & 14 & $(0.6)$ & & 6 & $(0.6)$ & 8 & $(0.7)$ & 0.61 \\
\hline \multicolumn{10}{|l|}{ Preshospital diagnosis and treatment } \\
\hline Initial ECG waveform & (VF or pulseless VT) & 59 & $(2.7)$ & & 31 & $(2.8)$ & 28 & $(2.5)$ & 0.66 \\
\hline Defibrillation provided by emergency medical personnel & (Performed) & 122 & (5.6) & & 56 & (5.1) & 66 & (6.0) & 0.39 \\
\hline Advanced airway device use & (Performed) & 546 & (24.9) & & 263 & $(24.1)$ & 283 & (25.6) & 0.42 \\
\hline Obtaining intravenous route & (Performed) & 284 & (12.9) & & 140 & (12.8) & 144 & (13.0) & 0.89 \\
\hline Epinephrine injection & (Performed) & 90 & $(4.1)$ & & 51 & $(4.7)$ & 39 & (3.5) & 0.18 \\
\hline Scene arrival time from emergency call (minimum) & & 7.77 & $(4.40)$ & $(0-51)$ & 7.73 & $(4.31)$ & 7.80 & $(4.49)$ & 0.71 \\
\hline Hospital arrival time from emergency call (minimum) & & 36.09 & (25.53) & $(5-324)$ & 37.00 & (28.19) & 35.20 & (22.59) & 0.10 \\
\hline \multicolumn{10}{|l|}{ Outcome } \\
\hline Return of spontaneous circulation before hospital arrival & (Yes) & 265 & $(12.1)$ & & 127 & $(11.7)$ & 138 & $(12.5)$ & 0.54 \\
\hline 1-month survival after the event & (Yes) & 263 & $(12.0)$ & & 120 & $(11.0)$ & 143 & $(13.0)$ & 0.16 \\
\hline Cerebral perfusion category & (1 or 2$)$ & 140 & $(6.4)$ & & 66 & $(6.1)$ & 74 & $(6.7)^{\prime}$ & 0.54 \\
\hline Overall performance category & (1 or 2$)$ & 140 & (6.4) & & 66 & (6.1) & 74 & (6.7) & 0.54 \\
\hline
\end{tabular}


Total cardiac arrest in Japan Between $1 / 1 / 2007$ and $12 / 31 / 2010$ $(n=461571)$

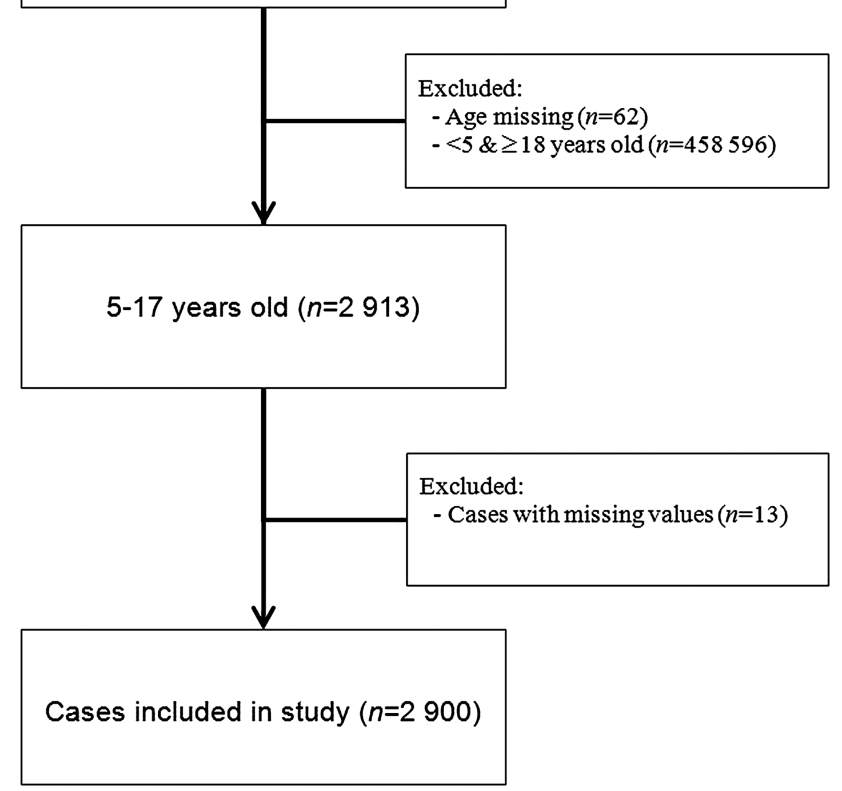

Figure 1 Cardiac arrest patients in Japan between 1 January 2007 and 31 December 2010 (n=2900).

\section{DISCUSSION}

By applying SDA to 2900 paediatric OHCA cases, out of about half million registered OHCA cases in the nationwide Utstein registry in Japan, we identified patient subgroups with varying contributing factors to predict the best neurological outcomes (CPC 1 or 2). The subgroups created by SDA in this study could help identify the best and worst practice scenarios for paediatric

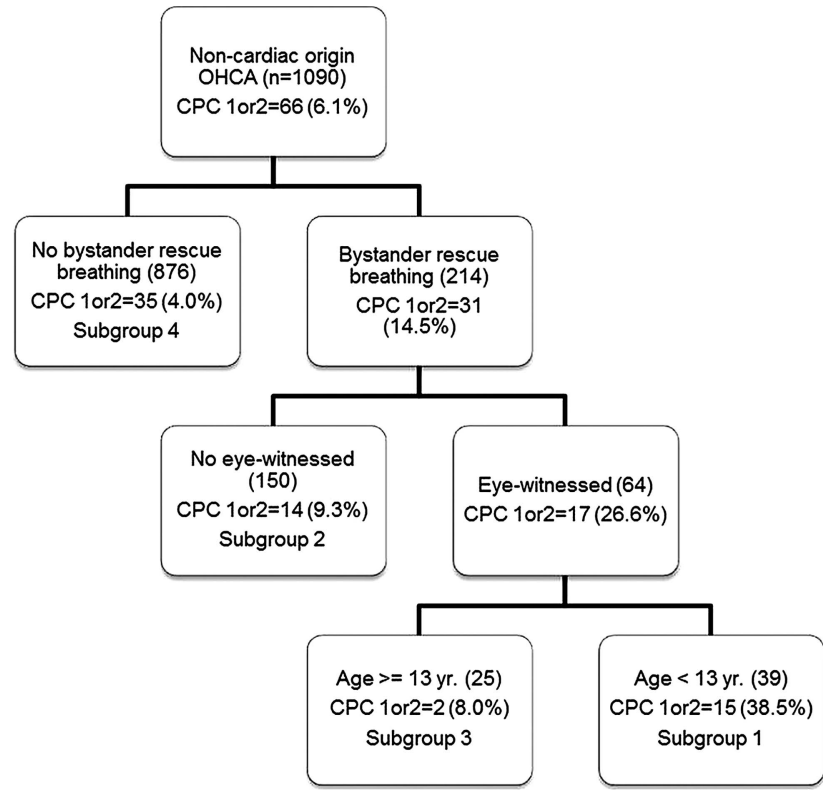

Figure 3 Results of signal detection analysis related to cerebral performance category 1 or 2 among 2007-2010 patients with out-of-hospital cardiac arrest aged 5-17 years: non-cardiac origin (patients were randomly split into two halves. One half was used for this analysis and the other half was used for validation).

resuscitation. Additionally, we confirmed the validity of these subgroups for the prediction of CPC 1 or 2 for OHCA in children by comparing a prediction sample with a validation sample. Furthermore, this study is the first to define subgroups of paediatric OHCA by longterm prognosis. Indeed, SDA revealed that public AED use was a significant predictor of CPC 1 or 2 outcomes for cardiac origin OHCA, and bystander rescue

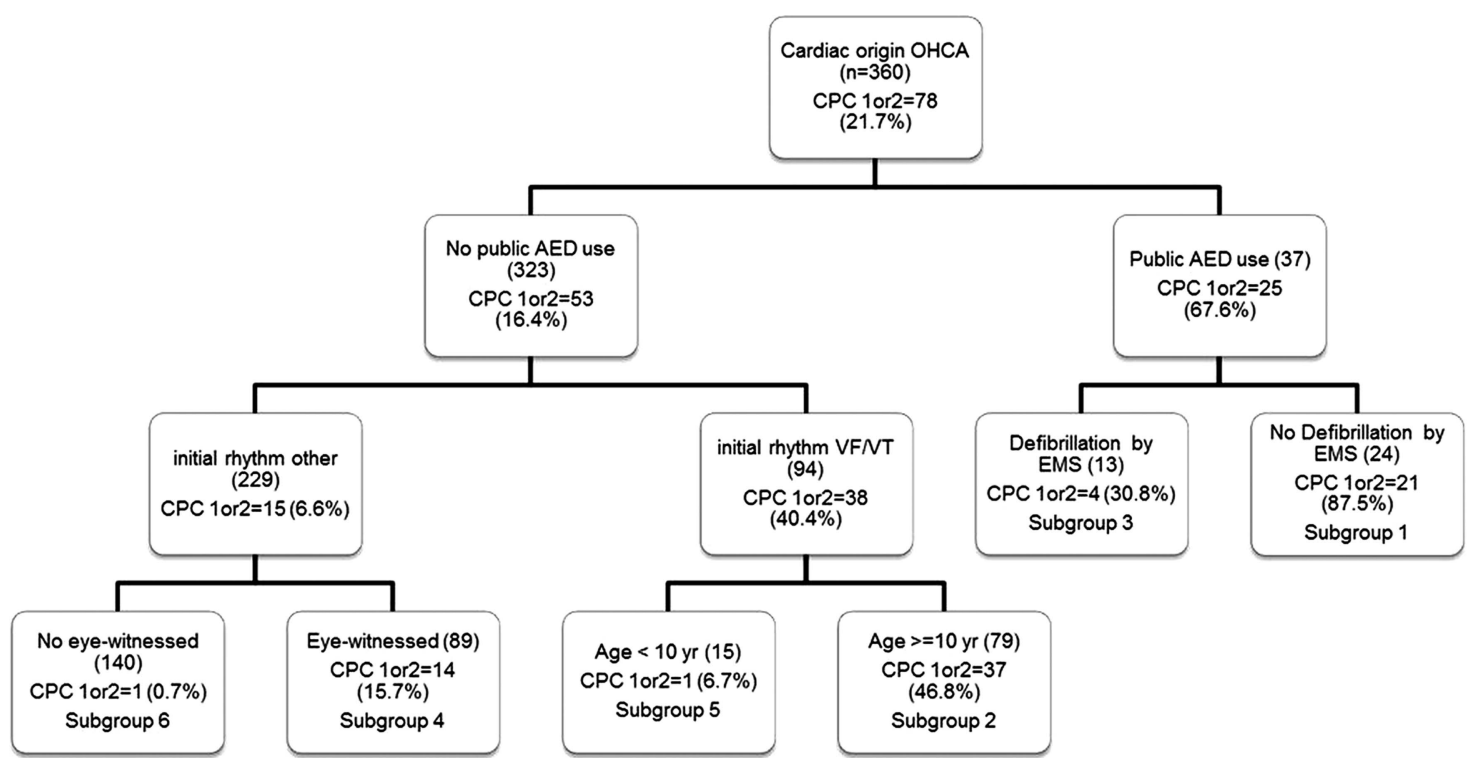

Figure 2 Results of signal detection analysis related to cerebral performance category 1 or 2 among 2007-2010 patients with out-of-hospital cardiac arrest aged 5-17 years: cardiac origin (patients were randomly split into two halves. One half was used for this analysis and the other half was used for validation). 
Table 3 Validity of randomisation, sample 1 versus sample 2, and performance by SDA among patients with OHCA with cardiac origin

CPC proportions SDA performance

\begin{tabular}{|c|c|c|c|c|c|c|c|c|c|c|c|c|c|}
\hline \multirow[b]{2}{*}{$\begin{array}{l}\text { Subgroup } \\
1(\%)\end{array}$} & \multirow[b]{2}{*}{$\begin{array}{l}\text { Subgroup } \\
2(\%)\end{array}$} & \multirow[b]{2}{*}{$\begin{array}{l}\text { Subgroup } \\
3(\%)\end{array}$} & \multirow[b]{2}{*}{$\begin{array}{l}\text { Subgroup } \\
4(\%)\end{array}$} & \multirow[b]{2}{*}{$\begin{array}{l}\text { Subgroup } \\
5(\%)\end{array}$} & \multirow[b]{2}{*}{$\begin{array}{l}\text { Subgroup } \\
6(\%)\end{array}$} & \multicolumn{5}{|l|}{$\mathrm{d}^{\prime}$} & \multicolumn{3}{|l|}{ AUC-ROC } \\
\hline & & & & & & $\begin{array}{l}\text { Public } \\
\text { AED } \\
\text { use }\end{array}$ & $\begin{array}{l}\text { No } \\
\text { defibrillation } \\
\text { by EMS }\end{array}$ & $\begin{array}{l}\text { Initial } \\
\text { rhythm } \\
\text { VFNT }\end{array}$ & $\begin{array}{l}\text { Age } 10- \\
17 \text { years }\end{array}$ & $\begin{array}{l}\text { Eye- } \\
\text { witnessed }\end{array}$ & c-statistics & $(95 \% \mathrm{Cl})$ & p Value \\
\hline \multicolumn{14}{|l|}{ Sample 1} \\
\hline $\begin{array}{l}87.5 \\
\text { Sample } 2\end{array}$ & 46.8 & 30.8 & 15.7 & 6.7 & 0.7 & 1.43 & 1.65 & 1.27 & 1.42 & 1.44 & 0.78 & (0.73 to 0.83$)$ & $<0.0001$ \\
\hline $\begin{array}{l}35.3 \\
\text { Total }\end{array}$ & 38.2 & 40.0 & 19.8 & 16.7 & 0.8 & 0.69 & -0.12 & 0.97 & 0.67 & 1.57 & 0.88 & (0.83 to 0.91$)$ & $<0.0001$ \\
\hline 65.9 & 42.9 & 36.4 & 17.9 & 9.5 & 0.7 & 1.06 & 0.76 & 1.12 & 1.13 & 1.52 & 0.83 & (0.80 to 0.86$)$ & $<0.0001$ \\
\hline
\end{tabular}

Cochran-Mantel-Haenszel test: $p=0.26$.

Subgroup 1: received public AED and did not receive defibrillation by EMS; 2 : not received public AED and with VF/VT of initial rhythm and in the age group of 10-17 years; 3 : received public AED and received defibrillation by EMS; 4: not received public AED and with non-VF/VT of initial rhythm and witnessed OHCA by a bystander; 5: not received public AED and with VF/VT of initial rhythm and in the age of 5-9 years; 6 : not received public AED and with non-VF/VT of initial rhythm and not witnessed OHCA by a bystander.

AED, automated external defibrillator; AUC-ROC, area under the curve in receiver operating curve; CPC, cerebral performance category; EMS, emergency medical service; OHCA,

out-of-hospital cardiac arrest; SDA, signal detection analysis.

Table 4 Validity of randomisation, sample 1 versus sample 2, and performance by SDA among patients with OHCA with non-cardiac origin

\section{CPC proportions}

\section{Subgroup 1 \\ (\%)}

Sample 1

38.5

Sample 2

21.7

Total

\begin{tabular}{lr}
$29.4 \quad 13.0$ \\
\hline Cochran-Mantel-Haenszel
\end{tabular}

13.0

Subgroup 2 (\%)

Subgroup 3 (\%)

Subgroup 4 (\%)

\section{SDA performance}

$\mathrm{d}^{\prime}$

Bystander rescue breathing

4.0

0.69

3.0

3.5

28.3

21.1

1.03

0.87

Subgroup 1: witnessed OHCA by a bystander and rescue breathing and with 5-12 years old; 2: not witness

AUC-ROC and received rescue breathing and in the age of 13-17 years; 5 : not received rescue breathing.

AUC-ROC, area under the curve in receiver operating curve; CPC, cerebral performance category; OHCA, out-of-hospital cardiac arrest; SDA, signal detection analysis.

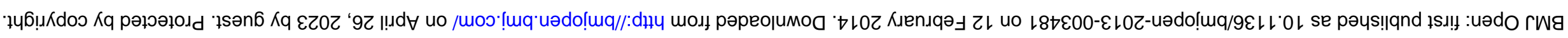




\begin{tabular}{|c|c|c|c|c|c|c|c|}
\hline & $\begin{array}{l}\text { Subgroup } 1 \text { ( } n=41 \text { ) } \\
\text { Patients: } \\
\text { Received public } \\
\text { AED } \\
\text { Not received } \\
\text { defibrillation by } \\
\text { EMS } \\
\text { Mean/\% }\end{array}$ & $\begin{array}{l}\begin{array}{l}\text { Subgroup } 2 \\
(\mathbf{n}=147)\end{array} \\
\text { Patients: } \\
\quad \text { Not received } \\
\text { Public AED } \\
\text { With VF/VT of } \\
\text { initial rhythm } \\
\text { In the age of } \\
10-17 \text { years } \\
\text { Mean/\% }\end{array}$ & $\begin{array}{l}\text { Subgroup } 3 \text { ( } \mathbf{n = 3 3}) \\
\text { Patients: } \\
\text { Received public } \\
\text { AED } \\
\text { Received } \\
\text { defibrillation by } \\
\text { EMS } \\
\text { Mean/\% }\end{array}$ & $\begin{array}{l}\text { Subgroup } 4 \text { ( } n=195) \\
\text { Patients: } \\
\text { Not received } \\
\text { public AED } \\
\text { With non-VF/VT } \\
\text { of initial rhythm } \\
\text { Witnessed } \\
\text { OHCA by a } \\
\text { bystander } \\
\text { Mean/\% }\end{array}$ & $\begin{array}{l}\text { Subgroup } 5 \\
\text { (n=21) } \\
\text { Patients: } \\
\text { Not received } \\
\text { public AED } \\
\text { With VF/VT of } \\
\text { initial rhythm } \\
\text { In the age of } \\
5-9 \text { years } \\
\text { Mean/\% }\end{array}$ & $\begin{array}{l}\text { Subgroup } 6(\mathrm{n}=\mathbf{2 6 9}) \\
\text { Patients: } \\
\text { Not received } \\
\text { public AED } \\
\text { With non-VF/VT of } \\
\text { initial rhythm } \\
\text { Not witnessed } \\
\text { OHCA by a } \\
\text { bystander } \\
\text { Mean/\% }\end{array}$ & p Value \\
\hline \multicolumn{8}{|l|}{ Basic information } \\
\hline Gender (male) & $70.7 \%$ & $68.7 \%$ & $78.8 \%$ & $62.6 \%$ & $61.9 \%$ & $54.6 \%$ & 0.014 \\
\hline Age (years) & 14.76 & 14.34 & 14.30 & 11.90 & 7.57 & 11.80 & $<0.001$ \\
\hline $\begin{array}{l}\text { Emergency life-saving technician } \\
\text { on ambulance ride (yes) }\end{array}$ & $97.6 \%$ & $93.9 \%$ & $100.0 \%$ & $96.4 \%$ & $100.0 \%$ & $96.3 \%$ & 0.479 \\
\hline $\begin{array}{l}\text { Medical doctor on ambulance } \\
\text { ride (yes) }\end{array}$ & $4.9 \%$ & $6.8 \%$ & $9.1 \%$ & $8.2 \%$ & $9.5 \%$ & $3.3 \%$ & 0.272 \\
\hline $\begin{array}{l}\text { Advance medical treatment by } \\
\text { medical doctor (yes) }\end{array}$ & $24.4 \%$ & $19.7 \%$ & $18.2 \%$ & $14.9 \%$ & $14.3 \%$ & $17.1 \%$ & 0.702 \\
\hline \multicolumn{8}{|l|}{ Witness and bystander CPR } \\
\hline $\begin{array}{l}\text { Eye witness of cardiac arrest } \\
\text { (yes) }\end{array}$ & $97.6 \%$ & $81.0 \%$ & $84.8 \%$ & $100.0 \%$ & $61.9 \%$ & $0.0 \%$ & $<0.001$ \\
\hline $\begin{array}{l}\text { Type of bystander (family } \\
\text { member) }\end{array}$ & $0.0 \%$ & $26.5 \%$ & $12.1 \%$ & $50.3 \%$ & $42.9 \%$ & $0.4 \%$ & $<0.001$ \\
\hline $\begin{array}{l}\text { Bystander chest compression } \\
\text { (performed) }\end{array}$ & $97.6 \%$ & $57.1 \%$ & $97.0 \%$ & $53.8 \%$ & $61.9 \%$ & $60.2 \%$ & $<0.001$ \\
\hline $\begin{array}{l}\text { Bystander rescue breathing } \\
\text { (performed) }\end{array}$ & $75.6 \%$ & $29.3 \%$ & $75.8 \%$ & $28.7 \%$ & $38.1 \%$ & $24.5 \%$ & $<0.001$ \\
\hline Bystander AED use (performed) & $100.0 \%$ & $0.0 \%$ & $100.0 \%$ & $0.0 \%$ & $0.0 \%$ & $0.0 \%$ & $<0.001$ \\
\hline \multicolumn{8}{|c|}{ Preshospital diagnosis and treatment } \\
\hline $\begin{array}{l}\text { Initial ECG waveform (VF or } \\
\text { pulseless VT) }\end{array}$ & $14.6 \%$ & $100.0 \%$ & $57.6 \%$ & $0.0 \%$ & $100.0 \%$ & $0.0 \%$ & $<0.001$ \\
\hline $\begin{array}{l}\text { Defibrillation provided by } \\
\text { emergency medical personnel } \\
\text { (performed) }\end{array}$ & $0.0 \%$ & $96.6 \%$ & $100.0 \%$ & $13.8 \%$ & $85.7 \%$ & $4.8 \%$ & $<0.001$ \\
\hline $\begin{array}{l}\text { Advanced airway device use } \\
\text { (performed) }\end{array}$ & $9.8 \%$ & $26.5 \%$ & $12.1 \%$ & $22.6 \%$ & $33.3 \%$ & $31.6 \%$ & $<0.01$ \\
\hline $\begin{array}{l}\text { Obtaining intravenous route } \\
\text { (performed) }\end{array}$ & $12.2 \%$ & $21.8 \%$ & $18.2 \%$ & $8.2 \%$ & $0.0 \%$ & $12.3 \%$ & $<0.01$ \\
\hline $\begin{array}{l}\text { Epinephrine injection } \\
\text { (performed) }\end{array}$ & $2.4 \%$ & $9.5 \%$ & $12.1 \%$ & $3.6 \%$ & $0.0 \%$ & $2.6 \%$ & $<0.01$ \\
\hline $\begin{array}{l}\text { Scene arrival time from } \\
\text { emergency call (minimum) }\end{array}$ & 7.51 & 6.31 & 5.94 & 6.82 & 6.43 & 6.67 & 0.082 \\
\hline $\begin{array}{l}\text { Hospital arrival time from } \\
\text { emergency call (minimum) }\end{array}$ & 27.98 & 33.73 & 31.79 & 30.62 & 31.57 & 33.16 & 0.609 \\
\hline
\end{tabular}




\begin{tabular}{|c|c|c|c|c|c|}
\hline & $\begin{array}{l}\text { Subgroup } 1 \text { ( } n=85) \\
\text { Patients: } \\
\text { Witnessed OHCA by a } \\
\text { bystander } \\
\text { Rescue breathing } \\
\text { With age } 5-12 \text { years } \\
\text { Mean/\% }\end{array}$ & $\begin{array}{l}\text { Subgroup } 2 \text { ( } \mathrm{n}=\mathbf{3 0 1}) \\
\text { Patients: } \\
\text { Not witnessed OHCA by a } \\
\text { bystander } \\
\text { Received rescue breathing } \\
\text { Mean/\% }\end{array}$ & $\begin{array}{l}\text { Subgroup } 3(\mathrm{n}=\mathbf{7 1}) \\
\text { Patients: } \\
\text { witnessed OHCA by a } \\
\text { bystander } \\
\text { received rescue } \\
\text { breathing } \\
\text { In the age of } 13- \\
17 \text { years } \\
\text { Mean } / \%\end{array}$ & $\begin{array}{l}\text { Patients: } \\
\text { Not received rescue } \\
\text { breathing } \\
\text { Mean/\% }\end{array}$ & p Value \\
\hline \multicolumn{6}{|l|}{ Basic information } \\
\hline Gender (male) & $64.7 \%$ & $65.8 \%$ & $64.8 \%$ & $63.9 \%$ & 0.937 \\
\hline Age (years) & 8.56 & 11.41 & 15.56 & 12.62 & $<0.001$ \\
\hline $\begin{array}{l}\text { Emergency life-saving technician on ambulance } \\
\text { ride (yes) }\end{array}$ & $95.3 \%$ & $95.7 \%$ & $91.5 \%$ & $94.5 \%$ & 0.555 \\
\hline Medical doctor on ambulance ride (yes) & $8.2 \%$ & $5.6 \%$ & $11.3 \%$ & $5.1 \%$ & 0.092 \\
\hline $\begin{array}{l}\text { Advance medical treatment by medical doctor } \\
\text { (yes) }\end{array}$ & $18.8 \%$ & $23.9 \%$ & $23.9 \%$ & $17.6 \%$ & 0.046 \\
\hline \multicolumn{6}{|l|}{ Witness and bystander CPR } \\
\hline Eye witness of cardiac arrest (yes) & $100.0 \%$ & $0.0 \%$ & $100.0 \%$ & $43.0 \%$ & $<0.001$ \\
\hline Type of bystander (family member) & $54.1 \%$ & $0.3 \%$ & $38.0 \%$ & $10.7 \%$ & $<0.001$ \\
\hline Bystander chest compression (performed) & $95.3 \%$ & $94.7 \%$ & $91.5 \%$ & $30.6 \%$ & $<0.001$ \\
\hline Bystander rescue breathing (performed) & $100.0 \%$ & $100.0 \%$ & $100.0 \%$ & $0.0 \%$ & $<0.001$ \\
\hline Bystander AED use (performed) & $2.4 \%$ & $2.0 \%$ & $7.0 \%$ & $0.1 \%$ & $<0.001$ \\
\hline \multicolumn{6}{|l|}{ Preshospital diagnosis and treatment } \\
\hline Initial ECG waveform (VF or pulseless VT) & $5.9 \%$ & $3.3 \%$ & $9.9 \%$ & $2.1 \%$ & $<0.001$ \\
\hline $\begin{array}{l}\text { Defibrillation provided by emergency medical } \\
\text { personnel (performed) }\end{array}$ & $10.6 \%$ & $7.0 \%$ & $12.7 \%$ & $4.8 \%$ & $<0.01$ \\
\hline Advanced airway device use (performed) & $18.8 \%$ & $27.9 \%$ & $22.5 \%$ & $24.8 \%$ & 0.338 \\
\hline Obtaining intravenous route (performed) & $7.1 \%$ & $17.6 \%$ & $16.9 \%$ & $12.3 \%$ & 0.018 \\
\hline Epinephrine injection (performed) & $1.2 \%$ & $5.6 \%$ & $5.6 \%$ & $3.9 \%$ & 0.235 \\
\hline Scene arrival time from emergency call (min.) & 8.01 & 8.39 & 8.38 & 7.62 & 0.022 \\
\hline Hospital arrival time from emergency call (min.) & 32.78 & 35.71 & 37.14 & 36.28 & 0.634 \\
\hline \multicolumn{6}{|l|}{ Outcome } \\
\hline Cerebral performance category ( 1 or 2 ) & $29.4 \%$ & $13.0 \%$ & $21.1 \%$ & $3.5 \%$ & $<0.001$ \\
\hline
\end{tabular}


breathing was a significant predictor for non-cardiac origin OHCA among children aged 5-17 years. In other words, in the best-case scenario for paediatric resuscitation, a patient receiving resuscitation by a bystander could expect a good outcome. In the worst-case scenario, a patient who did not receive bystander resuscitation possibly faces a poor outcome.

The most significant factor contributing to CPC 1 or 2 outcomes in paediatric cardiac origin OHCA is public AED use. ${ }^{127}$ However, subdividing our study population through SDA identified six groups with a wide variation in CPC 1 or 2 outcomes because of the contributions of other factors. Several explanations may account for this variation in CPC for paediatric cardiac origin OHCA. Subgroup 1 contained patients receiving public AED use, and patients in subgroup 3 received defibrillation by EMS in addition to public AED use. Subgroup 4 had non-VF/ VT (or pulseless electrical activity/asystole), but the cases were also eye-witnessed, which is expected to lead to immediate treatment by bystander and prehospital individuals. These subgroups were expected to have early intervention, and, accordingly, a better long-term prognosis. On the other hand, subgroup 6 could be described as non-witnessed, non-treatable initial ECG rhythm, no public AED use and death may have already occurred.

For non-cardiac OHCA, the most significant factor contributing to CPC 1 or 2 is bystander-performed rescue breathing. ${ }^{12}$ The comparison of CPC 1 and 2 between the individuals who received bystander rescue breathing or not was $10 \%$ different $(14.5 \%$ in rescue breathing and $4 \%$ in non-receiving rescue breathing). The American Heart Association (AHA) recommends chest-compression only CPR, a method supported by several studies ${ }^{28-30}$; however, this result suggested the potential effectiveness of bystander rescue breathing, and further study is mandatory for confirmation.

Interestingly, scene arrival time from emergency call and hospital arrival time from emergency call for noncardiac origin OHCA were statistically longer than those for cardiac origin OHCA. This may result from a smaller proportion of eye-witnessed cardiac arrest in non-cardiac cases, a longer time to confirm OHCA than for cardiac origin arrest, and potential delays in initiation of treatments such as bystander CPR.

The SDA findings are easily translatable to predict the clinical outcome of paediatric OHCA. For example, if a 9-year-old was diagnosed with cardiac-origin OHCA, had an initial ECG rhythm with VF/VT and no public AED was used on the scene, the probability of CPC 1 or 2 would be approximately $7 \%$ (as reflected by subgroup 5 ).

There are several limitations in this study. First, this study focused on OHCA in children, thus in-hospital cardiac arrests were not included. Also, the selected 17 explanatory variables mainly covered prehospital clinical situations. Therefore, the effectiveness of extracorporeal membrane or therapeutic hypothermia could not be confirmed in this study, and the details of pathophysiology and treatment of cardiopulmonary arrests were unknown. Second, because just 17 variables were selected, there exists the possibility of missing factors that might be significantly associated with better clinical outcomes, such as regional/geographical variances, temperatures, weather, etc. Third, bystander chest compression was significantly different between samples 1 and 2 among patients with non-cardiac arrest. However, outcome proportions were stable among subgroups. Thus, this would minimise a violation of homogeneity in two samples by randomisation. Fourth, although the validity of split-half by randomisation into samples 1 and 2 were warranted, the proportions by some subgroups seem different between samples (ie, $87.5 \%$ for sample 1 and $35.3 \%$ for sample 2 for subgroup 1 in patients with cardiac origin in table 3). Small sample size due to grouping after split-half could contribute to inconsistency, which might affect the generalisability of our findings. Compared with an adult population, paediatric patients consist of small proportions. ${ }^{12}$ Continuing data collection would improve the generalisability. Fifth, as for other epidemiological studies, data validity, integrity and bias should be taken into account. For example, the diagnosis of presumed cardiac arrest was decided exclusively, and non-cardiac cause was given when there was no obvious evidence of a cardiac arrest. Sixth, the performance of resuscitation for OHCA in children changes year by year, and this might not be fully reflected in the analysis. As shown in table 6, the percentages of eyewitness of cardiac arrest and bystander breathing were higher in 2009 compared with 2005 and 2008, probably because of improved public education on resuscitation in Japan. ${ }^{27}$

\section{CONCLUSION}

By applying SDA, contributing factors for the outcome of paediatric OHCA were identified. For cardiac OHCA, we identified five factors-public AED use, initial ECG rhythm, defibrillation, age and witnessed cardiac arrestcontributing to CPC 1 or 2. For non-cardiac OHCA, we identified three factors-bystander rescue breathing, witnessed cardiac arrest and age-contributing to CPC 1 or 2.

Author affiliations

${ }^{1}$ Faculty of Medical Sciences, Department of Advanced Medical Initiatives, Kyushu University, Fukuoka, Japan

${ }^{2}$ Faculty of Human Sciences, Waseda University, Tokorozawa, Japan ${ }^{3}$ Department of Emergency and Critical Care Medicine, Kyushu University Hospital, Fukuoka, Japan

${ }^{4}$ Ambulance Service Planning Division, Fire and Disaster Management Agency, Ministry of Internal Affairs and Communications, Tokyo, Japan ${ }^{5}$ Department of Health Services Management and Policy, Kyusyu University Graduate School of Medicine, Fukuoka, Japan

Contributors $\mathrm{AH}$ and $\mathrm{M}$ Hasegawa participated in study concept and design and acquisition of data. AH, M Hasegawa, TA, TN, EN and M Hashizume participated in analysis and interpretation of data, and administrative, technical or material support. AH and TN participated in drafting of the manuscript. AH, TN and TA participated in critical revision of the manuscript for important intellectual content. AH and TA participated in statistical analysis. AH participated in study supervision. 
Funding This research received no specific grant from any funding agency in the public, commercial or not-for-profit sectors.

Competing interests None.

Ethics approval The ethical committee of Kyushu University Graduate School of Medicine.

Provenance and peer review Not commissioned; externally peer reviewed.

Data sharing statement AH had full access to all of the data in the study and takes responsibility for the integrity of the data and the accuracy of the data analysis.

Open Access This is an Open Access article distributed in accordance with the Creative Commons Attribution Non Commercial (CC BY-NC 3.0) license, which permits others to distribute, remix, adapt, build upon this work noncommercially, and license their derivative works on different terms, provided the original work is properly cited and the use is non-commercial. See: http:// creativecommons.org/licenses/by-nc/3.0/

\section{REFERENCES}

1. Akahane M, Tanabe S, Ogawa T, et al. Characteristics and outcomes of pediatric out-of-hospital cardiac arrest by scholastic age category. Pediatr Crit Care Med 2013;14:130-6.

2. Nitta M, Iwami T, Kitamura T, et al. Age-specific differences in outcomes after out-of-hospital cardiac arrests. Pediatrics 2011;128: e812-20.

3. Hostler D, Thomas EG, Emerson SS, et al. Increased survival after EMS witnessed cardiac arrest. Observations from the Resuscitation Outcomes Consortium (ROC) Epistry-Cardiac arrest. Resuscitation 2010;81:826-30.

4. Topjian AA, Nadkarni VM, Berg RA. Cardiopulmonary resuscitation in children. Curr Opin Crit Care 2009:15:203-8.

5. Atkins DL, Everson-Stewart S, Sears GK, et al. Epidemiology and outcomes from out-of-hospital cardiac arrest in children: the Resuscitation Outcomes Consortium Epistry-Cardiac Arrest. Circulation 2009;119:1484-91.

6. Quan L. Adult and pediatric resuscitation: finding common ground. JAMA 2006:295:96-8.

7. Young KD, Gausche-Hill M, McClung CD, et al. A prospective, population-based study of the epidemiology and outcome of out-of-hospital pediatric cardiopulmonary arrest. Pediatrics 2004;114:157-64.

8. Donoghue AJ, Nadkarni V, Berg RA, et al. Out-of-hospital pediatric cardiac arrest: an epidemiologic review and assessment of current knowledge. Ann Emerg Med 2005;46:512-22.

9. Engdahl J, Axelsson A, Bang A, et al. The epidemiology of cardiac arrest in children and young adults. Resuscitation 2003;58:131-8.

10. Dumas F, Rea TD, Fahrenbruch $\mathrm{C}$, et al. Chest compression alone cardiopulmonary resuscitation is associated with better long-term survival compared with standard cardiopulmonary resuscitation. Circulation 2013;127:435-41.

11. Dumas F, Rea TD. Long-term prognosis following resuscitation from out-of-hospital cardiac arrest: role of aetiology and presenting arrest rhythm. Resuscitation 2012;83:1001-5.

12. Kitamura T, Iwami T, Kawamura T, et al. Conventional and chest-compression-only cardiopulmonary resuscitation by bystanders for children who have out-of-hospital cardiac arrests: a prospective nationwide, population-based cohort study. Lancet 2010;375:1347-54.
13. Hupfl M, Selig HF, Nagele P. Chest-compression-only versus standard cardiopulmonary resuscitation: a meta-analysis. Lancet 2010;376:1552-7.

14. Kiernan M, King AC, Kraemer HC, et al. Characteristics of successful and unsuccessful dieters: an application of signal detection methodology. Ann Behav Med 1998;20:1-6.

15. Kraemer HC, Noda A, O'Hara R. Categorical versus dimensional approaches to diagnosis: methodological challenges. J Psychiatr Res 2004;38:17-25.

16. Badriah F, Abe T, Nabeshima $Y$, et al. Predicting the length of hospital stay of psychiatry patients using signal detection analysis. Psychiatry Res 2013;210:1211-8.

17. Kleinman ME. Conventional cardiopulmonary resuscitation by bystanders improved outcomes in children with out-of-hospital cardiac arrest. Arch Dis Child Educ Pract Ed 2010;96:120.

18. Jacobs I, Nadkarni V, Bahr J, et al. Cardiac arrest and cardiopulmonary resuscitation outcome reports: update and simplification of the Utstein templates for resuscitation registries: a statement for healthcare professionals from a task force of the International Liaison Committee on Resuscitation (American Heart Association, European Resuscitation Council, Australian Resuscitation Council, New Zealand Resuscitation Council, Heart and Stroke Foundation of Canada, InterAmerican Heart Foundation, Resuscitation Councils of Southern Africa). Circulation 2004;110:3385-97.

19. Hagihara A, Hasegawa M, Abe T, et al. Prehospital lactated ringer's solution treatment and survival in out-of-hospital cardiac arrest: a prospective cohort analysis. PLoS Med 2013;10: e1001394

20. Hagihara A, Hasegawa M, Abe T, et al. Prehospital epinephrine use and survival among patients with out-of-hospital cardiac arrest. JAMA 2012;307:1161-8.

21. Abe $T$, Nagata $T$, Hasegawa $M$, et al. Life support techniques related to survival after out-of-hospital cardiac arrest in infants. Resuscitation 2012;83:612-18.

22. Group: W, Idris AH, Berg RA, et al. Recommended guidelines for uniform reporting of data from drowning: the "Utstein Style". Circulation 2003;108:2565-74.

23. Phelps R, Dumas F, Maynard C, et al. Cerebral performance category and long-term prognosis following out-of-hospital cardiac arrest. Crit Care Med 2013:41:1252-7.

24. Atienza AA, Yaroch AL, Masse LC, et al. Identifying sedentary subgroups: the National Cancer Institute's Health Information National Trends Survey. Am J Prev Med 2006;31:383-90.

25. Joseph Hair WB, Barry B, Rolph A. Multivariate data analysis. 7th edn. Upper Saddle River, NJ: Prentice Hall, 2010.

26. Meaney PA, Nadkarni VM, Cook EF, et al. Higher survival rates among younger patients after pediatric intensive care unit cardiac arrests. Pediatrics 2006;118:2424-33.

27. Kitamura T, Iwami T, Kawamura T, et al. Nationwide public-access defibrillation in Japan. N Engl J Med 2010;362:994-1004.

28. Rea TD, Fahrenbruch C, Culley L, et al. CPR with chest compression alone or with rescue breathing. $N$ Engl $J$ Med 2010;363:423-33

29. Kleinman ME, Chameides L, Schexnayder SM, et al. Pediatric advanced life support: 2010 American Heart Association Guidelines for Cardiopulmonary Resuscitation and Emergency Cardiovascular Care. Pediatrics 2010;126:e1361-99.

30. Field JM, Hazinski MF, Sayre MR, et al. Part 1: executive summary: 2010 American Heart Association Guidelines for Cardiopulmonary Resuscitation and Emergency Cardiovascular Care. Circulation 2010;122(18 Suppl 3):S640-56. 